\title{
Teaching nonscience majors about electromagnetic radiation
}

\author{
Shulamit Kapon $\circledast^{1, *}$ and Hagar Veksler ${ }^{2}$ \\ ${ }^{1}$ Faculty of Education in Science and Technology, Technion-Israel Institute of Technology, \\ Haifa 3200003, Israel \\ ${ }^{2}$ Faculty of Physics, Technion-Israel Institute of Technology, Haifa 3200003, Israel
}

(Received 7 July 2019; accepted 4 October 2019; published 4 December 2020)

\begin{abstract}
[This paper is part of the Focused Collection on Curriculum Development: Theory into Design.] We discuss the theoretical underpinnings that informed the considerations and decisions that shaped the design of a curriculum unit entitled "Electromagnetic radiation-principles, applications, and decisions". This unit is part $(45 \mathrm{~h})$ of the compulsory general science requirement for the Israeli high school matriculation curriculum in science for students who choose not to major in any scientific discipline. Its goal is to develop scientific literacy rather than expertise. During the problematizing phase that preceded the design we identified two challenges presented by the formal goal of the unit and its target audience: (i) how to foster meaningful engagement on the part of diverse groups of "outsiders to science" with complex scientific content such as electromagnetic radiation, (ii) how to translate scientific and engineering findings related to a complex phenomenon such as electromagnetic radiation, which emerge within a context of specialized knowledge and vocabulary, into lay language without corrupting their meaning. The first section of this article explores these questions through a theoretical discussion of (i) relevance, personal relevance, and meaningfulness; (ii) the implications of pursuing personal relevance on the meaning ascribed to scientific literacy of nonscientists, and the ways to support its development in school; and (iii) the ways in which personal relevance comes to bear on the choice of content and explanatory means. We then illustrate how these theoretical principles and insights were translated into curriculum design.
\end{abstract}

DOI: 10.1103/PhysRevPhysEducRes.16.020141

\section{INTRODUCTION}

This article discusses the theoretical underpinnings that informed the considerations and decisions which shaped the design of a curriculum unit entitled "Electromagnetic radiation-principles, applications, and decisions" [1]. The unit includes a textbook, and an online teachers' guide that were recently published in Hebrew and in Arabic (translation). It covers a unit ( $45 \mathrm{~h}$ ) from the compulsory general science requirements for Israeli high school matriculation for students who choose not to major in any scientific topic at the advanced level. Teachers of general science choose two units out the eight listed to cover the compulsory requirement. The goal of the general science matriculation, according to the Israeli Ministry of Education that commissioned the design, is to develop scientific literacy rather than expertise. The official rationale behind this requirement resonates with international policies which state that

\footnotetext{
*skapon@technion.ac.il
}

Published by the American Physical Society under the terms of the Creative Commons Attribution 4.0 International license. Further distribution of this work must maintain attribution to the author(s) and the published article's title, journal citation, and DOI. citizens of democratic societies need to develop knowledge, understanding, and skills to make personal decisions, and take an active part in public debates related to socioscientific issues that may have a direct impact on their lives [2-4].

The target audience for the curriculum is high school students who by definition are "outside the STEM pipeline" [5]. These teens (aged 16-17) are either not interested or unable to pursue a future STEM career. Most of them only take the minimal mathematics requirement for matriculation. Some of them plan to study humanities, art, or other subjects at the university that do not have an advanced-level science matriculation prerequisite, and based on their experience with science courses in middle school (grades 7-9) they decide to study other topics at the advanced level in high school. However, for most of them, learning a specific scientific discipline at the advanced level is not even feasible in high school. Either they did very poorly in their middle school science and mathematics classes (and developed strong negative feelings toward the subject the same time) or are enrolled in private schools in which the compulsory matriculation requirement is the only science track possible. Israel is highly diverse in terms of culture, ethnicity, religion, and socioeconomic status, and students clearly reflect this diversity. 
During the problematizing phase that preceded the design, we identified two challenges presented by the formal goal of the unit and its target audience. We articulate them in this article as two research questions:

1. How to foster meaningful engagements of diverse groups of "outsiders" [5] with complex scientific content such as electromagnetic radiation?

2. How to translate scientific and engineering findings related to a complex phenomenon such as electromagnetic radiation, which emerge within a context of specialized knowledge and vocabulary, into lay language without corrupting their meaning [6,7]?

In the following sections we first describe the theoretical considerations that shaped and guided our thinking in addressing the challenges articulated by the research questions, and then illustrate the ways in which these principles were manifested in the design of the unit.

\section{CONCEPTUAL FRAMEWORK}

\section{A. Fostering meaningful engagements of outsiders with complex scientific content}

Informed by constructivist approaches to learning, we planned to design the curriculum around student-centered activities. Hence, we asked ourselves what kind of activities the students in this educational context should engage in, what would make these activities meaningful, and to whom. Our theoretical consideration of these questions employed a reverse engineering approach, since meaningfulness is a relative construct. A prerequisite for understanding if something is meaningful to a person, community, or organization is to first identify the target person, community, or organization to understand their values and goals.

Berland et al. [8] employ the term "meaningful use" to characterize how they perceive meaningful students' engagement in scientific practices. They define meaningful use as students" "use of particular epistemic ideas to make progress on epistemic goals that are meaningful to the classroom and scientific communities" (p. 1085). Hence the "whom" here is the classroom community and the scientific community. By "meaningful to the classroom community" the authors "mean not that all students find the same knowledge construction goal compelling at all times, but instead to communicate that the classroom activities are organized around a goal that the students understand and recognize as the type of goal that their classroom community tends to work towards. This requires that students be aware of the purpose of their actions and that they experience their actions as directed toward that purpose." (p. 1087). By "meaningful to the scientific community" the authors mean that taken together, the practices the students engage in "pursue the overarching goal of developing evidence-based, explanatory models of the how and why the natural world works in the ways that it does" (p. 1085), consistent with the overarching goal of the scientific endeavor [9].

The rationale for engaging students in scientific practices stems from the goal to foster disciplinary authenticity in science classrooms [10-12]. Berland et al. [8] describe engagement in scientific practice that is meaningful to the classroom community as engagement in which the students do not technically follow the teacher's direction, but rather know why they engage in the particular practice, and grasp how it coheres with the larger goals of the classroom community. Note that this definition of meaningfulness does not require the epistemic goals in question to be important or even valued by the students at a personal level. The requirement is that the rationale for their use in the classroom context be understood.

It is reasonable to hope that if students who choose to study scientific disciplines at the advanced level in high school are well taught, they will appropriate [13] the epistemic goals of science in the sense that they will start using them spontaneously to make sense of the world outside of the classroom context for their own purpose. The likelihood that this might be true of students who actively avoid science in high school seems much smaller. Several case studies of public understanding of science have examined how people who were not academically trained in science engaged with science in the context of real-life problems. The findings suggest that knowledge of particular school-based scientific concepts and practices did not play a significant role in their reasoning, whereas knowledge about science and its epistemology enabled these individuals to frame meaningful questions, even in contexts in which relevant science concepts were inaccessible to nonscientists [14].

Note that we do not question the importance of engaging students who are "in the pipeline" with doing science. This engagement promotes the development of expertise [15], and when well crafted can become deeply meaningful to these students at a personal level. In fact, a significant portion of our research group's activities is dedicated to this end [11,16-18]. However, this is not the audience of the general science curriculum that we designed. The rest of this section thus takes the perspective of personal relevance [11] to critically examine the effectiveness of engaging outsiders in disciplinary authentic practices of doing science as a way to develop their scientific literacy, and suggests an alternative.

In an article that analyzed the core practices detailed by the NGSS [19], Osborne [20] discusses scientific literacy as a manifestation of the NGSS core practice of "obtaining, evaluating and communicating information" in science: "In short, writing and arguing are core activities for doing science [21,22]. Indeed, as Norris and Phillips [23] point out, the fundamental sense of literacy in science is the ability of an individual to construct meaning through interaction with the multiple forms of 
semiotic communication that are used within the discipline of science" (p. 188).

An underlying premise behind this argument is that the cognitive and culturally organized activities that scientists engage in as they "obtain, evaluate and communicate information" when "doing science" are identical to those nonscientist adults employ when addressing challenges that have scientific aspects (e.g., how to react to a planned installation of a cell tower in one's neighborhood). Feinstein [24] claims that this premise is not supported by empirical evidence. Based on a review of studies in public understanding of science and reasoning in everyday experience, he argues that the cognitive and culturally organized activities that outsiders to science engage in when addressing challenges related to science are very different. For example, the individuals in these studies rarely framed their challenge as scientific, and when showing interest in related scientific research, these individuals were usually interested in the results of a specific clinical study, rather than the underlying principles and methods [25]. Moreover, even when science was initially identified as a relevant framing for the challenge, it was only one facet of a far more complex framing. Hence in addressing the challenge these individuals collectively constructed scientific and nonscientific knowledge with other individuals in their community [26].

The engagement of these individuals with science started from a problem or challenge that was personally meaningful to them, in the sense that they perceived the problem or challenge as directly affecting or relating to their lives rather than being situated in a "pure" scientific context. Feinstein [27] articulated the related pedagogical challenge as helping these individuals to become "competent outsiders" rather than "marginal insiders" to science. The lens of personal relevance is particularly germane to addressing this pedagogical challenge.

Building on an extensive literature review on the use of the term relevance in science education, Stuckey et al. [28] modeled this use as reflecting three dimensions: (i) an individual dimension that relates to students' intellectual skill development; (ii) a societal dimension that relates to the students' competency for current and future societal participation; and (iii) a vocational dimension that relates to students' orientation and preparation for future professions and careers, and further academic or vocational training. They argued that relevance as described by each dimension presents aspects that are relevant to students in the present or may become relevant to them in the future. They further argued that each dimension has an intrinsic component in the sense that the students are the agents who decide what is relevant, or an extrinsic component in the sense that society, parents, or any other external agents get to decide what is relevant in that dimension. Scientific literacy as conceptualized in the writings cited above $[19,20,23]$ reflects only extrinsic relevance. The notion of personal relevance, on the other hand, is entirely intrinsic.
Kapon, Laherto and Levrini [11] defined personal relevance in science education as encompassing students' sense of benefit, value, meaning, and agency as users and generators of what is learned. They conceptualized school science, disciplinary authenticity, and personal relevance as representing three distinct perspectives on STEM education, and argued that their mutual pursuit in educational contexts generates tensions that need to be resolved, and that the tensions and their resolutions are manifested very differently in different educational contexts. Based on a literature review, they identified five different facets along which these tensions are manifested: content fidelity, content coverage, language and discursive norms, epistemic structure and standards, and significance.

Personal relevance in terms of content fidelity [11] implies that students should develop their agency as individual thinkers who can create knowledge. Tension with school science may arise when students reach conclusions that contradict "correct" ideas. Personal relevance in terms of content coverage [11] implies that the curriculum is largely emergent and discovered "on the fly" based on students' ideas, interests, and difficulties. Hence coverage of a predefined curriculum in a predefined time is quite challenging when seriously pursuing this approach (for classroom studies that illustrate tensions with content fidelity and coverage see Refs. [29-32]).

Science is often implicitly presented at school as superior to other culturally based ways of knowing. However, culturally based epistemologies and discourses play an important role in students' lives. Personal relevance in terms of language and discursive norms [11] implies that students' culturally based language and discursive norms are explicitly recognized as legitimate discourse in the classroom [33,34]. Personal relevance in terms of epistemic structure and standards implies that students' cultural ways of experiencing and knowing are explicitly recognized as legitimate ways of knowing. From a personal relevance perspective, students should learn to navigate between multiple legitimate epistemologies rather than be expected to abandon their previously held ways of knowing. Some scholars pursue this goal by designing science curricula that are tailored to a particular culture (e.g., Native American communities [35,36]), while others (more in line with our curriculum) suggest presenting science as one of many legitimate ways of knowing [37]. The second approach invites students to compare and contrast scientific explanations of phenomena with other culturally based explanations of the same phenomena, and explicitly discuss the contexts in which each is more appropriate [37]. While these studies mainly deal with the teaching of science to indigenous communities, we found them insightful as regards educational designs that aim to engage nonscientists with science to develop their scientific literacy, since these individuals' language, discursive norms, and ways of knowing differ significantly from the language, discursive 
norms, and ways of knowing that characterize professional science.

A study that examined sustained interest in science in urban minority youth [38] found that these individuals "developed a sustained interest in science when (1) their science experiences connected with how they envision their own futures, (2) learning environments supported the kinds of social relationships students valued, and (3) science activities supported students' sense of agency for enacting their views on the purpose of science." (p. 466). Personal relevance in terms of significance [11] implies that students perceive the content and the nature of the activities they engage in as contributing, empowering and transformative to their lives.

A personal relevance approach to the pedagogical challenge of developing scientific literacy among nonscientists coheres with how Feinstein [24] defines the empirical approach to science literacy. The description of what science literacy looks like in this approach is based on when and how science is useful to students' present and future daily lives. It thus corresponds to the significance facet of personal relevance. The decision as to which knowledge, skills and attributes should be taught in this approach is based on in situ studies of nonscientists' engagement with science in real-life situations, and consequently builds on scientific and nonscientific resources. Hence this aspect corresponds to the content fidelity, content coverage, language and discursive norms, and epistemic structure and standards facets of personal relevance.

\section{B. Translating complex scientific and engineering content into lay language without corrupting its meaning}

Physics presents a body of knowledge that is highly hierarchical. The underlying physics of real-life applications of electromagnetic radiation is quite complex and is systematically learned only in upper division undergraduate or graduate courses $[39,40]$ since it requires substantial prior knowledge in mathematics and physics. Our thinking about this challenge was guided by the translated scientific explanations (TSE) framework [41,42]. The TSE framework suggests explanatory pathways to "translate" scientific and engineering findings related to a complex phenomenon which emerge within a context of specialized knowledge and vocabulary into lay language without corrupting their meaning.

The TSE framework is composed of four clusters of explanatory elements. The first cluster is termed the analogical approach [42]. It includes explanatory elements such as positive [43] or negative [44] analogies, bridging analogies [45], visual analogies [46], metaphors [47], and category extension [48]. Explanatory elements in this cluster explain the unknown in terms of the known. The rich literature on the cognitive origins, nature, and functions of each element highlight pathways for effective use with students. Examples include the explicit mapping of source onto target, or explicit discussions that highlight the boundaries of the analogical inference applicability [49].

The second cluster is termed the story [42] and includes explanatory elements that help in constructing scientific ideas through means that are common in literature (fiction), such as narratives (i.e., protagonists involved in an event or a plot) [50,51], humor, and cognitive conflict. The use of explanatory elements from the story cluster resonate deeply with specific facets of the perspective of personal relevance; i.e., language and discursive norms, and epistemic structure and standards, since people organize their experiences and memory of events mainly in the form of stories [52].

The third cluster of the TSE framework is termed knowledge organization [42] and is aimed at helping students follow the argument, by assisting them in recalling important concepts and ideas that were taught early in the unit and serve as necessary prior knowledge for its more advanced parts. Components include repetitions of important ideas in various ways, explications of the outline and objectives of arguments, using visual aids such as tables and flowcharts, presenting well thought out and coherent structures for the arguments, etc.

The fourth cluster of the TSE framework is termed content [42]. It reflects the judicious choice of what to include, what to omit, and means to achieve this goal through the selection of topics and formats, and the omissions and simplifications employed. Tensions arise in particular in this cluster between disciplinary authenticity [11], which calls for accountability to the conceptual and epistemological features of science, its social dialectical practices, and affective features, school science (highstake tests, predefined curriculum, etc.), and personal relevance [11]. These tensions need to be resolved, mainly with regard to content fidelity, content coverage, and epistemic structure and standards.

\section{THEORY-INFORMED DECISIONS WITH RESPECT TO CURRICULUM DESIGN}

\section{A. An empirical approach to science literacy}

The design of the unit on electromagnetic radiation was commissioned by the Israeli Ministry of Education, which stipulated that a predefined set of topics as specified by the official matriculation syllabus needed to be covered. However, we did not use this list as our starting point. Instead, we used it as a checklist when the first draft was completed, and in the few cases where something was missing we added it. Since both of us (authors) have mainly been teaching physics to relatively strong students "in the pipeline," before we planned the structure of the unit, we felt that we had to learn more about our target student and teacher audiences. We were particularly interested in figuring out the nature and context of the conundrums and challenges that these individuals are likely to encounter 
or be exposed to in their daily lives where scientific knowledge of electromagnetic radiation might become useful. We were also interested in the resources they have available and are likely to employ in their reasoning, the kind of arguments they have and often use, and what they would like to know about electromagnetic radiation.

In the first 6 weeks of the project, and throughout the writing of the first draft, we investigated these issues. We visited an authentic general science classroom in a large urban school, observed lessons, and had informal talks with the students and their teacher. Before we started to write and throughout the writing of the first draft we also set up meetings with about 40 teachers who teach general science at the high school level, about 30 of them during a four-day professional development course in which they experienced some of the beta versions of the activities we were developing, as learners. We discovered that most teachers who teach the general science course are biology teachers, who do not like and are somewhat afraid of physics. However, as we found out, they were very curious about the related socioscientific issues. When they realized that we were willing to answer any question they had, also by email, their feedback as learners became invaluable. At a later phase of the design some of these teachers also implemented the activities in their classrooms and their feedback led to the refinement of some of the activities.

With the help of the science communication group at the Faculty of Education in Science and Technology at the Technion, we met people from the Israel Ministry of Environmental Protection that are involved in legislation and public affairs related to electromagnetic radiation. We also watched numerous TV shows and podcasts (news or general media) on electromagnetic radiation, and read blogs and websites by nonscientists dealing with electromagnetic radiation. The second author also had a long visit with Mr. Amir Borenstein, a nonscientist blogger who has written on the hazards of nonionizing electromagnetic radiation [53] for more than a decade, and who has recently also started to sell online measurement devices and shielding accessories for personal and family use. As he explains in his blog, his interest and related civil activism on the topic started because he suffers from symptoms that modern medicine did not know how to diagnose and cure. His readings on his symptoms led him to the conclusion that they are caused by electromagnetic hypersensitivity (EHS). EHS is not recognized as a physical illness by the Israeli Ministry of Health or by the World Health Organization [54]. Some of the officials and colleagues we talked to expressed resentment at Amir's activism, and argued that it stirs up unjustified fears of modern technology. We felt that Amir's activism exemplifies authentic nonscientist citizen engagement with science. In our view science education that aims for scientific literacy cannot and should not dismiss or patronize such arguments, but rather should seriously and respectfully engage with them, particularly because nonscientists find them compelling.
This informal investigation led to important insights. First, it highlighted authentic real-life contexts in which nonscientists engage with issues that are closely related to electromagnetic radiation. We anticipated many of these contexts, such as medical examinations, cancer, sunscreens (Israel has a very warm climate), the use of UV light in gel nail polish, safe use of cellular phones and cellular towers, and wi-fi. However, some of these topics were only discovered during our informal investigations. One example is the above-mentioned issue of electromagnetic hypersensitivity that appeared to be quite popular in the public media. Another is the issue of radiation emitted by electric household appliances, fuse boxes, and high voltage lines. In terms of "pure" physics this is not what is termed electromagnetic radiation since this phenomenon stems from the near field region of the electromagnetic field, which is measurable because of the very low frequency of the current $(50 \mathrm{~Hz})$. However, in our informal investigation we came across many individuals who referred to it as electromagnetic radiation (reporters on popular investigative TV shows, technicians who are called to private homes to measure radiation, as well as publications for the general public produced by the Israeli Ministry of Environmental Protection). The term electromagnetic radiation was used even though the measured quantity was very different (magnetic field rather than power per square meter), and the fact that there is very rapid decrease in the magnitude of the field when one moves away from the source.

Another insight that emerged from the informal investigation was that pseudoscientific arguments are abundant and appear very compelling to nonscientists. Examples include "proving" a claim by referencing a particular result from one study, while ignoring the abundance of findings from many other studies that have found the opposite or critique the method, or by citing the personal experiences of one individual. We realized that we needed to embed aspects that highlight the nature, the affordances, and the limitations of scientific based answers in our activities, as well as determine which individuals can and cannot be considered science experts and in which contexts.

\section{B. Fostering a sense of significance, negotiating epistemologies, and respectfully engaging with nonscientific language and discursive norms}

Two general realizations emerged from our informal investigation as well as our reading of studies on public engagement with science. The first was that we need to convince the students from the very beginning of the unit, and again in every chapter, that the science content and epistemology that they are studying is highly relevant to their daily lives; namely, addressing the significance facet of personal relevance. The second was that the activities we want the students to engage in and the explanations we provide should reflect a respectful and productive negotiation and integration of scientific knowledge with other 
ways of knowing that are naturally evoked when nonscientists think about the problems at hand; namely, addressing the language and discursive norms and epistemic structure and standards facets of personal relevance. Our design worked toward this goal by employing explanatory means from the story cluster in the TSE framework [42].

We used a "frame tale," an introductory narrative that introduces the protagonists (see below) and the rationale for the unit (Chap. 1, "Why radiation"), and a closing narrative that revisits this rationale in retrospect (Chap. 11, "Epilogue-Electromagnetic radiation in the media"). Our frame tale used an authentic documentary entitled "How we kill ourselves-Radiation" [55] that was produced and broadcast by a large TV network in Israel. The author and presenter of this documentary, a well-known TV host in Israel, discusses the hazards of nonionizing electromagnetic radiation in a series of interviews with various scientists and physicians who specialize in different aspects of the phenomenon, as well as concerned representatives from the general public, such as parents who are worried about the Israeli Ministry of Education initiative to install wi-fi in public schools, a person who suffers from EHS, who discussed the symptoms she was suffering from in detail, and how moving to a secluded town abroad, in which any use or transmission of electromagnetic radiation is prohibited, cured her of most of the symptoms she was suffering from.

The network agreed to freely release the documentary over the internet, and we decided to use it as the frame tale for our unit, since it grounds the scientific discussion in problems that the students would immediately see as deeply affecting their lives, and would stimulate many questions that intrinsically motivate a discussion of the scientific concepts that we wanted to discuss; i.e., establishing significance. The documentary also illustrates (in our view) the chasm between the discourse of the scientist and nonscientist interviewees, almost as though they were on parallel planes, manifesting a tension between personal relevance and disciplinary authenticity in terms of language and discursive norms, and epistemic structure and standards. The message that appeared to emerge from this very interesting documentary is that indeed "we kill ourselves," although none of the expert scientists or physicians stated that at all. We saw an opportunity to openly discuss discursive differences with the students, and use this discussion to help them to (i) differentiate scientific discourse from other legitimate discourses, and (ii) understand what science "can buy" them, and what it cannot. The main activity in the first chapter in the unit invites teachers and students to watch the documentary, and then engage in an activity that aims to help them differentiate facts from opinions in the claims made in the documentary, and highlight questions and issues that receive unambiguous answers from those that do not. We ended the unit with an activity on this documentary (Chap. 11, "EpilogueElectromagnetic radiation in the media"). Building on the previous chapters, the last chapter starts with a brief review of characteristic differences between scientific discourse and discourse in the media. The closing activity asks the students to watch the documentary again after having studied the related scientific content and identified the characteristic of scientific discursive norms. The students are asked to discuss the following questions with their classmates: "(i) Can we infer from what the scientists and physicians said in the interviews that they think that we kill ourselves by our use of nonionizing electromagnetic radiation? If not, specify what each scientist or physician actually claims. (ii) What kind of evidence did each of the stakeholders who were interviewed (scientists and nonscientists) rely on? Do you agree with them? Explain why." (p. 131, Hebrew textbook). Note that this assignment closes the unit. Unlike the opening assignment, here the focus is mainly on what the scientists say (Q1). Our design goal here was not to lead the students to embrace the scientific view, but rather to teach them how to interpret correctly scientific claims, regardless of whether they accept or do not accept them. We disagree with the prevalent assumption that "evidence-based claims and arguments" is what distinguishes scientific claims from nonscientific claims [56]. Nonscientists employ evidence-based arguments and claims all the time. The difference is in the epistemic standards of what counts as solid evidence, and whether and to what extent the limitation of the conjectures that can be drawn from the evidence are explicitly stated. Competent outsiders need to understand these discursive norms and epistemic standards to be able to correctly interpret scientific discourse and productively employ it when they make decisions on socioscientific issues.

The unit was designed around a series of studentcentered activities. However, the activities were embedded within a story that had several protagonists, each implicitly representing a different perspective, epistemological stance, and interest in the issue of electromagnetic waves (again, explanatory means drawn from the story cluster of the TSE framework [41,42]). Figure 1 present the protagonists of the main story (as opposed to the frame tale). The protagonists have typical Hebrew names that implicitly reference their identity (e.g., the first name of the environmental activist is Haim, the Hebrew word for life, and his last name is Green as in the characteristic color of plants). The names of the protagonists in Fig. 1 are those that appear in the Hebrew version. To preserve the humorous reference to their identities (i.e., story cluster), these names were changed appropriately in the Arabic translation.

Many of the explanations, questions and perspectives we wanted to elicit were triggered or presented though short dialogues between these protagonists. For example, Fig. 2 presents a dialogue from the first chapter that was prompted by a statement in the book that says that the Ministry of Environmental Protection established 


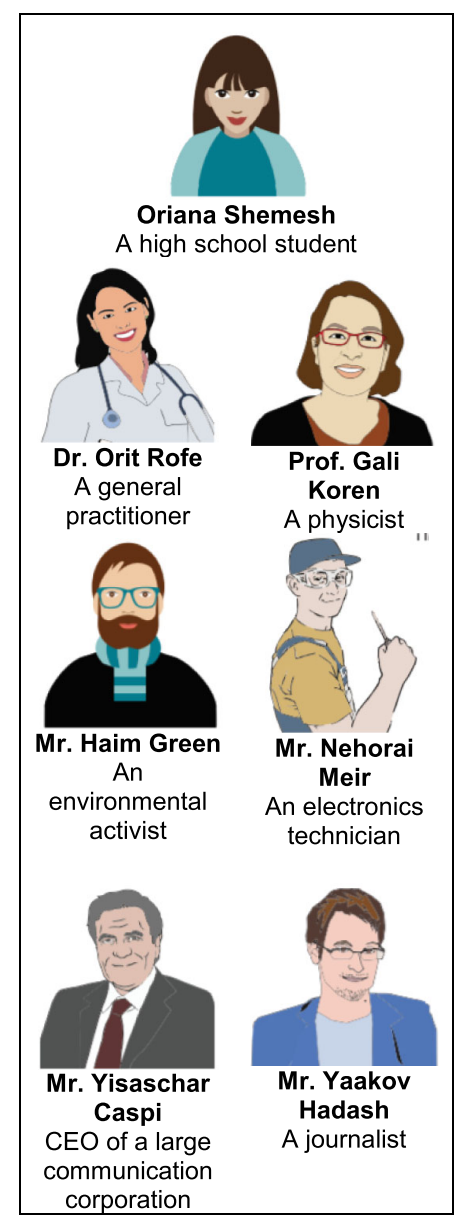

FIG. 1. The protagonists.

standards for maximum safe exposure to radiating devices. The goal of this dialogue was to elicit and legitimize different views on the question of using technology. In this first chapter, the term electromagnetic radiation has not yet been differentiated from the term radiation, and thus at this stage the protagonists only use the term radiation.

We often used Oriana (the teen protagonist) in these dialogues to ask questions that students might think of and might not feel comfortable about asking (i.e., addressing the facet of language and discursive norms). Figure 3 presents an example of the use of these dialogues to explain something. These dialogues always appear in the book over a light purple background, and the pictures of the participating protagonists are always placed in a small header on the top left (see Figs. 2 and 3). Note that in both examples (Figs. 2 and 3) the scientist is not the only one to explain. Ronit Peretz, a "test teacher," who taught the entire beta version of the unit told us enthusiastically that some of her students spontaneously started to role-play many of these dialogues during the lessons, and "performed" them for their peers.

Professor Gali Koren, and the physician (general practitioner) Dr. Orit Rofe, are heard in the textbook more frequently than the nonscientist protagonists, and when speaking they often have a greater number of lines. Note that this inequality is not a manifestation of a tension between school science and personal relevance in terms of epistemic structure and standards. Rather, it reflects a tension in terms of content coverage, as the textbook is part of a curriculum in science. Presenting science as one of many legitimate ways of knowing, in our view, does not mean that other ways of knowing should be systematically taught in science lessons, or that they should be considered as science [11]. Students are familiar with these ways of knowing. In science lessons these ways of knowing should be acknowledged as legitimate ways of knowing when they are relevant to the discussion, and explicitly connected to the discussions. At the same time, they should be

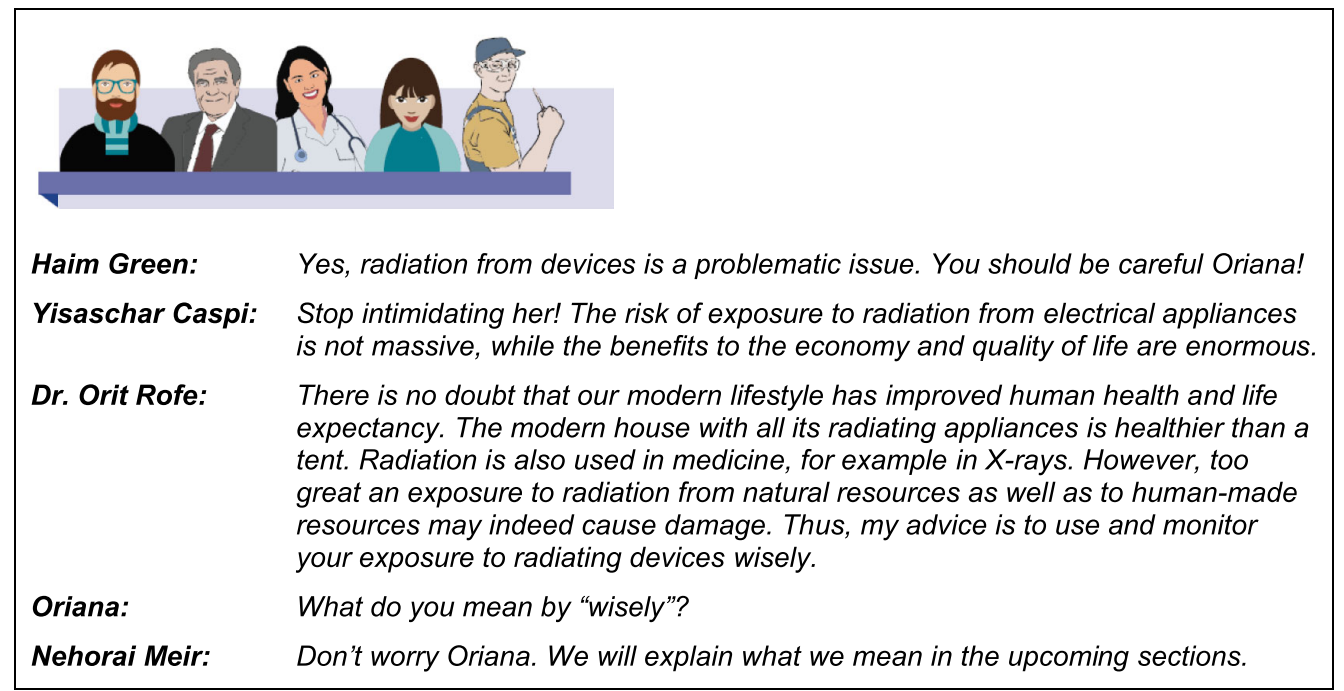

FIG. 2. An example of a discussion between some of the protagonists aimed at eliciting various legitimate perspectives (Chap. 1, Why radiation? [1]). 


\begin{tabular}{|c|c|}
\hline Oriana: & $\begin{array}{l}\text { Yesterday I read in the newspaper that a "wave of accidents" has hit the } \\
\text { country. }\end{array}$ \\
\hline Yaacov Hadash: & $\begin{array}{l}\text { Yes. Sometimes we use the term wave to describe a group of similar } \\
\text { phenomena, or sudden phenomena that are very strong. A wave of accidents, } \\
\text { a wave of terrorist attacks, a wave of generosity, etc.. The meaning of the } \\
\text { word wave in this expression differs from the scientific meaning of the term } \\
\text { wave. There are many words in our language that have different meanings in } \\
\text { different contexts. For example, the word mouse can refer to an animal in one } \\
\text { context and to a computer accessory in another. }\end{array}$ \\
\hline Oriana: & $\begin{array}{l}\text { But I always know if we are talking about an animal or my computer mouse. } \\
\text { How can I tell that something is a wave in the scientific meaning of the term? }\end{array}$ \\
\hline Prof. Gali Koren: & $\begin{array}{l}\text { When we use the term wave in science, we can identify a disturbance that } \\
\text { propagates in a medium that does not move. When we create a wave in a } \\
\text { Slinky ((refers to a previous activity)),/.../ as soon as we create the wave we } \\
\text { know what the spring will look like. On the other hand, for the 'wave of } \\
\text { accidents' in the news, nothing propagates. /.../ knowing where the first } \\
\text { accident took place cannot help us predict where the next accidents will take } \\
\text { place. They are simply a set of unrelated events. The use of the word wave in } \\
\text { the news and in a scientific context can be quite different! }\end{array}$ \\
\hline
\end{tabular}

FIG. 3. An example of an explanatory discussion between some of the protagonists (taken from Chap. 2, "What is a wave?" [1]).

explicitly differentiated from the scientific way of knowing. This differentiation does not mean that science is "superior"; rather, it provides a basis to identify contexts of reasoning in which scientific way of knowing is more (or less) productive to reason with, and can help competent outsiders to correctly interpret explanations offered by scientists.

Our presentation of the issue of electromagnetic hypersensitivity, although only taking up a minute portion of the unit (see Fig. 4), illustrates what we mean by respecting different ways of knowing while illustrating the nature, affordances, and limitations of scientific ways of knowing.

When discussing this issue with officials, the take-home message that we were given was that people who suffer from EHS have mental problems. At first we thought that we should ignore EHS, although our informal investigation suggested that it occasionally appears in the media and would certainly interest the students. But after some thinking we decided that we should discuss it. The EHS interviewee in the documentary felt better after moving to the secluded town, in which any use or transmission of electromagnetic radiation is prohibited. We believe that she was not imagining feeling better, and thus for her this was legitimate evidence. At the same time, it was important for us to explain why this experience cannot establish a scientifically based causal relation or even a connection that can be generalized. In fact, when we talked to a physician at a leading hospital in Israel, she stressed that indeed so far there is no compelling evidence for a biological cause of EHS symptoms. However, she did not dismiss the clinical symptoms these patients report.
Dr. Orit Rofe's (our physician protagonist) comment in Fig. 4 thus reflected this respectful authentic discourse.

At first glance, one might argue that exposing students to noncanonical perspectives, such as the ones presented in the documentary for instance, which the students might adopt, is in conflict with content fidelity from a schoolscience perspective. We argue that the way we approached it suggests ways to resolve this tension. Our initial informal investigation and our reading of the literature on public understanding of science suggested that students are likely to encounter these non-canonical perspectives in out-of-school contexts. Engaging with these perspectives in a science lesson provides opportunities to highlight the relevance of science knowledge in these debates. While our own personal epistemology related to these issues is more in line with science, we do not presume that students will embrace the scientific way of knowing and abandon their prior epistemologies after the course. Studies in science communication suggest that people's decisions about socioscientific issues are strongly affected by their cultural identity, and when this identity is threatened, when they have some scientific background, they use bits and pieces of scientific information to support their cultural identity [57]. Thus, we intentionally did not want to put students in a culturally defensive position. We saw our design goal much more modestly: to teach students how to make knowledgebased decisions about socioscientific issues related to electromagnetic radiation, identify when scientific information should be considered, and correctly interpret it in their decision making; for example, by being able to 


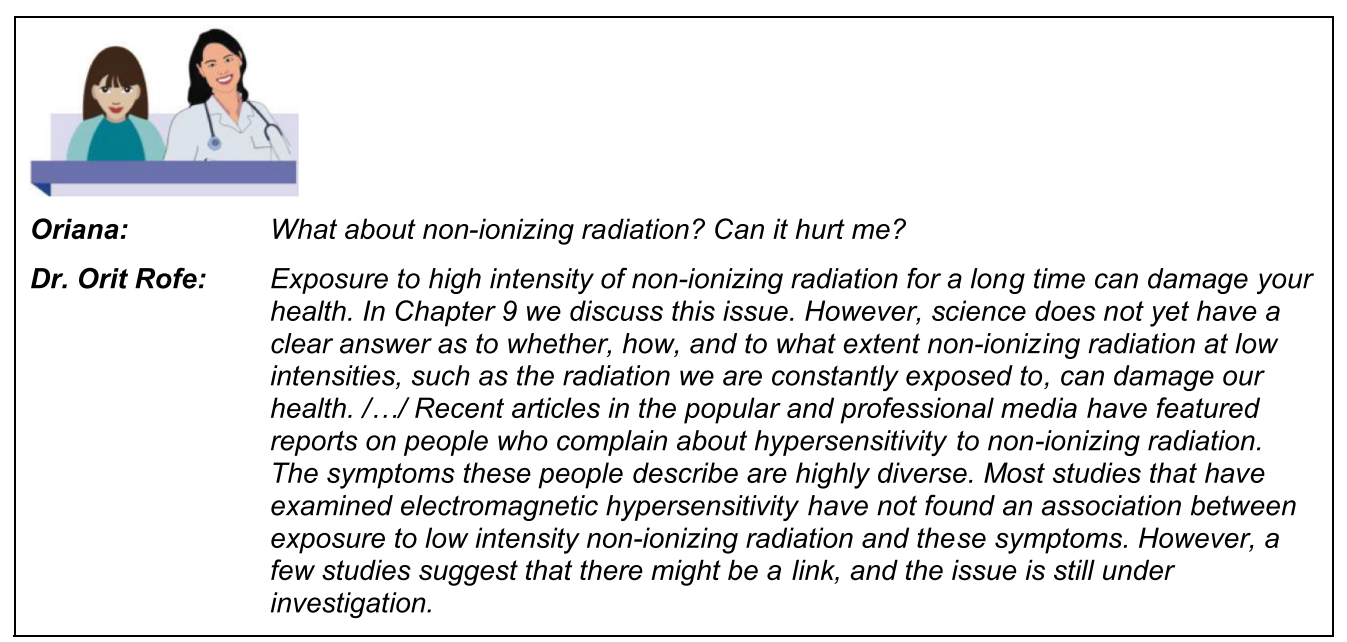

FIG. 4. Discussing electromagnetic hypersensitivity (taken from Chap. 6, "The electromagnetic spectrum" [1]).

differentiate well established from rudimentary scientific findings.

Some of the activities we designed could be characterized as inquiry activities. However, they were not intended to be authentic scientific inquiries, but rather "competent outsider" inquiries. For example, when discussing the effects of the electromagnetic radiation from the sun on the human body, we engage the students in an activity in which they use UV beads to examine the effect of different measures used for sun screening. We purposely do not spend time defining the independent and dependent variables in the experiment, or problematizing and eliciting a research question. The activity is aimed at helping the students answer a question that interests them; namely, which measure (different brands of sunscreen lotions with various sun screen indices, clothing, sunglasses, etc.) provides the most efficient protection from the sun (i.e., establishing significance from a personal relevance point of view). Our scaffolding aims at helping the students reach a reliable conclusion. This activity sparked genuine interest that was manifested in both the adults' (i.e., the teachers) and the students' enthusiastic insistence on testing not just the few sun-protection measures we brought to class, but also the cosmetics, makeup, clothing, and sunglasses they had in their bags.

The next example also highlights an inquiry that cannot be classified as an authentic scientific inquiry, but rather is more closely aligned with practicing engagement with science as competent outsiders' and in which students have many opportunities to talk about science using everyday language (i.e., personal relevance in terms of language and discursive norms). The activity appears at end of Chap. 6 that discusses the electromagnetic spectrum. The second author shortened and paraphrased three media items that covered issues related to the electromagnetic spectrum. In this activity, our journalist protagonist, Mr. Yaacov Hadash tells the students that his newspaper wants to hire a new science reporter. He explains that after reading the applicants' CVs the editorial board chose three finalists, and requested a writing sample from each. He asks the students to help the editorial board choose the best candidate. First the students are asked to answer a list of questions with regard to each writing sample: "(i) What part of the spectrum does the item discuss? (ii) What is the scientific information provided (facts, questions, and explanations)? (iii) To what extent is this information clearly presented to nonexperts? (iv) What is the relevance of the item to our daily lives? Explain. (v) Does the report rely on trustworthy and reliable resources? Explain. (vi) Is the report objective? Explain. (vii) What do you think is the reporter's personal stance with regard to the topic of the report? (viii) What do you think might improve the item?" [1] (Hebrew version, p. 75). After answering these questions, the students are asked to hold a class discussion on which reporter they think should be hired and why.

\section{Choice and coverage of scientific content}

Given our initial goal to maximize the engagement of students, most of the book is written around various activities $(N=38)$. The authentic real-life examples of engagement of nonscientists with issues related to electromagnetic radiation that we identified in our informal investigation formed the basis for many of the activities we designed. We also used them to figure out the scientific knowledge that could help nonscientists better resolve the challenges presented by these authentic engagements, in accordance with principles and explanatory means from the knowledge organization cluster in the TSE framework [42]. Table I presents the titles of the chapters and the main scientific concepts that are discussed in each.

Some of the scientific concepts that appear in Table I are not part of the official syllabus, and were added based on our informal investigation described above. In terms of scientific content, Chaps. 2-5 gradually build up the 
TABLE I. Scientific content.

\begin{tabular}{|c|c|}
\hline Chapter title & Main scientific concepts \\
\hline 1. Why radiation? & $\mathrm{N} / \mathrm{A}$ (introduction) \\
\hline 2. What is a wave? & Wave, medium, disturbance, propagation of a disturbance \\
\hline 3. Sound waves & Sound waves \\
\hline 4. Periodic waves & $\begin{array}{l}\text { Periodic wave, period, frequency, wavelength, amplitude, the velocity of } \\
\text { propagation, the energy of the wave }\end{array}$ \\
\hline 5. Electromagnetic radiation & $\begin{array}{l}\text { Electric field, magnetic field, electromagnetic radiation, measurements of } \\
\text { electromagnetic radiation, standards for exposure to electromagnetic } \\
\text { radiation }\end{array}$ \\
\hline 6. Electromagnetic spectrum & $\begin{array}{l}\text { The electromagnetic spectrum (radio, microwaves, infra-red, visible light, } \\
\text { ultraviolet, x rays, Gamma rays), ionizing and non-ionizing radiation }\end{array}$ \\
\hline $\begin{array}{l}\text { 7. Transmission, reflection, and absorption } \\
\text { of waves }\end{array}$ & Transmission, reflection, absorption \\
\hline 8. Visible light & $\begin{array}{l}\text { Refraction, black, white, RGB, the human eye (cornea, pupil, iris, lens, } \\
\text { retina, cone and rod cells) }\end{array}$ \\
\hline $\begin{array}{l}\text { 9. The impact of electromagnetic radiation on the } \\
\text { human body }\end{array}$ & $\begin{array}{l}\text { Damage caused by radiation, specific absorption rate (SAR), sun protection } \\
\text { factor (SPF) }\end{array}$ \\
\hline $\begin{array}{l}\text { 10. Medical applications of electromagnetic } \\
\text { radiation }\end{array}$ & $\begin{array}{l}\text { Imaging, x-ray radiography, computed tomography }(\mathrm{CT}) \text { scan, magnetic } \\
\text { resonance imaging (MRI), radioisotope scan }\end{array}$ \\
\hline $\begin{array}{l}\text { 11. Epilogue-Electromagnetic radiation in the } \\
\text { media }\end{array}$ & $\begin{array}{l}\text { Characteristics of scientific discourse (e.g., how a causal relation is } \\
\text { established) }\end{array}$ \\
\hline A1. Units of measurement & Definitions of all the units used in the book \\
\hline A2. Glossary & Definitions of all the concepts mentioned in the book \\
\hline
\end{tabular}

scientific basis for productively engaging with sociocultural issues related to electromagnetic radiation. In these chapters we explain the required concepts and ideas, through activities that employ demonstrations, real-life examples, and various visual devices. In Chap. 2 we define the term wave and the difference between the everyday use of the term (e.g., "a wave of violence") and its scientific meaning. In Chap. 3 we briefly discuss sound waves. Note that sound waves are not part of the compulsory syllabus, but we briefly discuss this phenomenon quite early in the unit, since we use it to bridge over missing prior knowledge that we could not fully explain due to our students' limited background in physics and mathematics. The "bridges" we used are explanatory elements from the analogical approach cluster in the TSE framework [42]. For example, by contrast to waves in a string or in water, students cannot see the vibration of sound waves in the same way that they cannot see the vibration in electromagnetic waves. However, unlike electromagnetic waves, students can hear the vibration of sound waves and easily distinguish sound waves with different frequencies or amplitudes. This attribute makes soundwaves a powerful bridging analogy [45] between visible mechanical waves (e.g., waves in water) and electromagnetic waves. We also used other features of sound waves as a source analogy to explain abstract ideas related to electromagnetic waves. For example, in Chap. 7 we compare the transmission of speech via a tin-can telephone and cellular phones by engaging students in experimenting what might impede successful transmission in each case.
One of the insights we derived from our informal investigation is that people think of electromagnetic radiation as a mystery in the sense that they cannot imagine what vibrates. We wanted to demystify this notion. In Chap. 4 we explain the basic scientific terms associated with periodic waves to productively engage in real-life socioscientific challenges related to electromagnetic radiation. In Chap. 5 we introduce electromagnetic waves. The chapter begins with an intuitive explanation of electric and magnetic fields, although these are not concepts that are included in the predefined syllabus. We felt that students should have an intuitive sense of these concepts since they are the entities that vibrate in electromagnetic waves. Hence the inclusion of these topics (i.e., content coverage) was motivated by a disciplinary perspective on scientific literacy. We then engaged students in a series of activities using various kinds of analogies, PhET and other simulations, visual devices, and demonstrations to help the students grasp what oscillates (i.e., explanatory devices from the analogical approach and content clusters [42]). For instance, we used a microwave to light an incandescent light bulb to give the students a sense that there is indeed an oscillating electric field. Another way to demystify electromagnetic waves is presented in the activity in Fig. 5 which uses an analogy. The activity scaffolds students' understanding of a positive analogy [44] between waves in a string and radio waves by comparing two PhET simulations that provide a visual analogy [46] between the two.

To support a sense of relevance to everyday life even in this very scientific chapter, we designed an activity that 


\section{Activity $\mathbf{5 . 2}$}

$\cdots$

4. There is a strong visual resemblance between the simulation of electromagnetic waves you just played with and the one you recently employed to investigate waves in a string.

- Open both simulations side-by-side.

- Draw a line between the isomorphic descriptions, actions, and objects in the two cases

(Solution)

Electromagnetic waves

https://phet.colorado.edu/en/simula

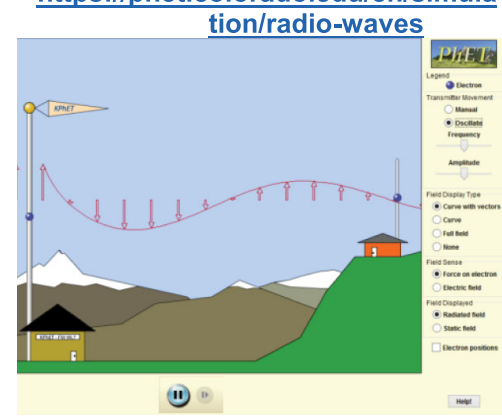

- Wiggling the transmitter electron to create a sudden change electric current

- Oscillate the transmitter electron automatically at a constant rate to create a periodic disturbance

- The rise and fall in the magnitude of the magnetic and electric fields.

- The propagating disturbance is the change in the magnitude and direction of the electromagnetic fields.
Waves in a string

http://phet.colorado.edu/sims/wave-

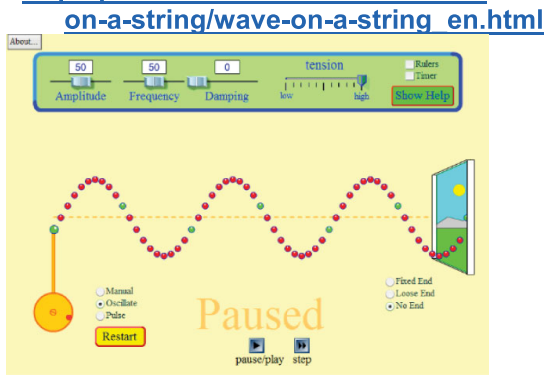

- Wiggling the string

- Wiggling the string at a constant rate using the oscillator

- The increase and decrease of the height of the string

- The propagating disturbance is the change in the height of the string relative to its equilibrium state

\section{Notice the limits of the isomorphism:}

- The string is the medium through which the mechanical waves propagates. Without it there can be no waves. In contrast, electromagnetic waves do not need a medium in order to propagate. They can also propagate in a vacuum.

- Moreover, waves in a string only propagate along the string, whereas the electromagnetic waves transmitted from the antenna in the simulation propagate in all directions, although only one direction is illustrated in the simulation.

FIG. 5. Part of an activity to scaffold the construction of knowledge using a positive visual analogy between radio waves and waves in a string (taken from Chap. 5, "Electromagnetic radiation" [1]).

engages students in reasoning with electromagnetic radiation measurements taken at home with radiation meters that are sold to the general public over the internet. The activity uses screenshots of home measurements with this type of device. The students are asked to interpret these measurements using standards for exposure to electromagnetic radiation that are available to the general public on the Israeli Ministry of Environmental Protection website.

In terms of scientific content, Chaps. 6-10 (see Table I) expand and deepen the presentation of additional properties of electromagnetic waves and their uses in everyday life. Chapter 6 discusses the electromagnetic spectrum, Chap. 7 discusses issues related to the transmission, absorption and reflection of waves, Chap. 8 expands on phenomena related to the visible spectrum, which was added later to comply with the requirements of the official predefined syllabus, Chap. 9 discusses the influence of electromagnetic radiation on the human body, and Chap. 10 discusses medical uses of electromagnetic radiation. The scientific information in the book, particularly in Chaps. 8-10, is not restricted to physics and also includes ideas and concepts from biology and medicine. The content and activities in these chapters explain ideas in physics that we would probably not have systematically dealt with in an advanced level classroom on electromagnetic waves, since they are less germane to an understanding of the underlying scientific principles and practices. In contrast, our informal investigation suggested that they were important to making sense of the relevant socio-scientific issues. One example is the concept of specific absorption rate (SAR), how it is 
measured in cellphones and reported in their specifications. SAR is the rate at which energy is absorbed by the human body when exposed to a radio frequency. The official standards require discussing with the students the effects of electromagnetic radiation on the human body in general. The concept of SAR, or any other term used to quantitatively evaluate the effects of electromagnetic radiation were not included in the official syllabus of general science. We felt that from a disciplinary perspective on scientific literacy (as opposed to personal relevance), this was an incorrect pedagogical decision, since quantitative estimations of risks are a central epistemic feature in scientific discourse. Competent outsiders should be able to understand what scientists mean when they discuss risks. We decided to include SAR in the textbook because it affords opportunities to engage students in analyzing the quantitative specifications of their cell phones (we designed an activity that invites them to compare different brands), which immediately creates a sense of significance from a personal relevance perspective. This discussion also affords exemplification of how standards of safety are dynamically established and employed (i.e., establishing significance from a societal and scientific perspective). Similarly, the official syllabus requires teachers to discuss the effects of radiation from the sun on the human body and how to protect the body from the hazards involved, without referring to specific quantitative measures. Israel has a warm climate and people purchase sun screen products frequently. We felt that competent outsiders should be able to understand the specification of the products they use (and SPF is the most prevalent specification) just as they should be able to understand the specification of nutrition factors listed on the food they choose to purchase. Hence here again the decision of what was relevant was extrinsic. Significance in terms of personal relevance was established by designing an activity that examined the efficacy of prevalent sunscreen measures (see the previous section).

Note that adding content to the unit required the omission of other content. For example, the older general science units on electromagnetic radiation encompassed many aspects of geometric optics which we decided to ignore. These included the formation of shadows, camera obscura, mirrors, thin lens, etc. We negotiated these issues with officials from the Ministry of Education. The addition of Chap. 8, in which we expand on the visible light part of the electromagnetic spectrum without relating to aspects of geometric optics resulted from these negotiations.

The textbook also has two Appendixes. The first Appendix provides definitions of all the units used in the book, although we also defined them in the text when first presented. The emphasis on understanding the meaning of units cannot be justified by arguments related to personal relevance. Its relevance is extrinsic rather than intrinsic, and stems from the fundamental role of units in scientific discourse. We noticed that productively engaging in socioscientific discourse sometimes requires an understanding of a numerical result, and numbers in science do not have meaning without units. The second Appendix provides a list of concise definitions of all the scientific concepts mentioned in the textbook. Both Appendixes were designed to help students easily recall the meaning of recently learned terms. To further support the learners' knowledge organization and particularly since the textbook is written around activities and narratives, we list the key scientific concepts and terms to be learned in a small box at the beginning of each chapter, and provide a concise summary of the main scientific ideas at the end (i.e., explanatory devices from the knowledge organization cluster of the TSE framework [42]). We also included multiple choice questions for self-assessment.

\section{DISCUSSION}

We described and provided examples of the theoretical underpinnings that informed the decisions and guided the design of a curriculum unit entitled "Electromagnetic radiation-principles, applications, and decisions". This unit is part of a compulsory general science graduation requirement for students who do not take any courses in a scientific discipline at the advanced high school level.

The course was commissioned by the Israeli Ministry of Education, which predefined the coverage (topics and skills) and the goal of the curriculum (i.e., scientific literacy, informed citizenship, etc.). The Ministry's reasoning was primarily that the older curriculum units on electromagnetic radiation were no longer relevant given the rapid changes in the related technology (i.e., content). We agreed with this reasoning, as well as the rationale for the compulsory matriculation requirement in general science, which states that even non-scientist citizens in democratic societies need to develop a certain level of scientific literacy to productively take part in public debates and decisions on socio-scientific issues [2-4]. However, we felt that this rationale expressed the point of view of the Israeli centralized educational system. It did not express in any way the voice of our target students. These students explicitly chose not to study any scientific discipline in high school. They sign up for the general science course because they have no choice if they want to graduate. We felt that we had to figure out how and why learning about electromagnetic radiation could become relevant and meaningful to them and reflect this understanding in the design. In this article, these concerns were formulated as the two research questions presented in the introduction. The first was how to foster meaningful engagements of diverse group of outsiders to science with complex scientific content such as electromagnetic radiation. The second was how to translate scientific and engineering findings related to a complex phenomenon such as electromagnetic radiation, which emerge within a context of specialized knowledge and vocabulary, into lay language without 
corrupting their meaning. Our thinking about these questions, which was later transformed into a specific design, was guided and informed by theory.

The response to the first question is rooted in the definition ascribed to the terms relevance and meaningfulness, and how these meanings project onto the meaning ascribed to the term scientific literacy. In the science education literature, relevance has been discussed with regard to students' development of intellectual skills, their competency for productive societal participation, and their preparation for future professions and careers [28]. These dimensions are often defined solely and externally by society, parents, and the nature of the discipline, not by students. However, these dimensions can and should reflect the students' point of view as well. We feel that any curriculum, and particularly a science curriculum for this group of students, must be meaningful to students at a personal level, because otherwise they will not meaningfully engage in the learning process [38] and we will be wasting their time. Achieving meaningfulness requires constant tradeoffs when resolving the tensions between personal relevance, school science, and the scientific discipline. Specifically, our design aimed at nurturing a sense personal relevance; namely, the students' sense of benefit, value, meaning, and agency as users and generators of what is learned [11], while also adhering to the scientific and societal aspect of relevance. We realized that taking this perspective seriously would have implications in terms of the choice of content, the language, and discursive norms used. It would also affect the ways of knowing students are engaged with in the unit, and how these discursive norms and ways of knowing are legitimized in the classroom.

Based on an extended literature review the National Academies of Sciences, Engineering, and Medicine (NASEM) [58] defined seven aspects of scientific literacy, which reflect "what many scholars expect would be useful or valuable" (p. 32). The NASEM note that only three of these aspects are common to most applications of the term scientific literacy: content knowledge, understanding of scientific practices, and cultural understanding of science. The other four aspects; namely, foundational literacies (e.g., numeracy), epistemic knowledge, identifying and judging scientific expertise, and dispositions and habits of mind, are less common. A position paper titled "Can science literacy help individuals identify misinformation in everyday life?" [59] argues that the less represented aspects are actually those that can really help nonscientists deal and identify misinformation which is so prevalent in the media. Specifically, these authors, who were prompted to examine this issue from their studies in science communication, argue that epistemic knowledge, identifying and judging scientific expertise, dispositions and habits of mind such as open mindedness, and understanding of scientific practices (in the more general sense of what scientists do and how to interpret scientific findings, rather than knowledge and skills necessary to do science, such as collecting and analyzing data), are aspects of scientific literacy that are crucial for the productive decision making of nonscientists about socioscientific issues. These ideas, which represent an extrinsic view of relevance (i.e., scientific, societal, and institutional views), strongly cohere with the theoretical idea of helping non-STEM major students to become competent outsiders rather than marginal insiders [5,27] which we adopted while approaching the problem of scientific literacy from a personal relevance perspective [11].

We had to reconsider our thinking of scientific literacy and the kinds of activities that foster its development in nonscientists. Our survey of the literature on public understanding of science as well as our informal investigation convinced us that the cognitive and culturally organized activities in which 'outsiders to science' engage in when addressing challenges related to science in their daily lives are different from those scientists employ when "doing science" [5,27]. Hence, although strongly advocated $[20,23]$, in our opinion, engaging our target group of students in related authentic scientific practices did not seem to be a productive strategy to promote their scientific literacy. On the other hand, engaging them in activities that correspond with informed authentic engagement of nonscientists with science, in which reasoning and decisions naturally involve the negotiation of science with other legitimate ways of knowing, seemed much more productive. We realized that we should design such activities and help our students productively engage in them. The analysis in the previous section suggests several related design principles: (i) Do not assume a priori what students should know, but rather empirically and open- mindedly search for real-life authentic contexts in which nonscientists can benefit from knowledge of science to make productive decisions. (ii) Identify the minimal scientific knowledge required for productive participation in socioscientific debates on the topic in question, and use various explanatory means to explain it and connect it to students' lives. (iii) Engage students in activities that correspond with practices that nonscientists employ when they engage with science, instead of engaging them in authentic scientific practices. (iv) Do not place students in a culturally defensive position by discussing scientific epistemology as superior, or implicitly assume that "they will see the light" after you teach them. Instead, think of science as another way of knowing, and help students understand what scientific epistemology is, how to correctly interpret scientific claims, and consider contexts in which these interpretations might be applicable. (v) Do not ignore other ways of knowing. This does not mean that we should give equal weight to nonscientific epistemologies in terms of time in science lessons or treat nonscientific ways of knowing as science. Instead, we should explicitly and respectfully acknowledge other ways of knowing, and 
design activities that invite negotiations between science and other forms of knowing by examining the context and goal of reasoning in each case.

In terms of content, the underlying physics behind modern applications of electromagnetic radiation is very complex, and we used a rich set of explanatory means as described by the TSE framework [42] to bridge the gaps in the students' prior knowledge and support their learning. As shown in Table I we "covered" a great deal of physics in the unit. However, designing the unit around activities that reflect competent outsiders [5,27] engagement with science, and the specific choice of content and explanatory devices, in particular the abundant and unorthodox use of the explanatory elements from the story cluster [42] were targeted to support the students' sense of personal relevance and their productive participation in socioscientific engagement as competent outsiders. Had the target body of students for the curriculum been high school students who are studying physics at the advanced level, the outcomes of the design would have been radically different.
[1] H. Veksler and S. Kapon, Electromagnetic RadiationPrinciples, Applications, and Decisions (textbook in Hebrew, textbook in Arabic, and online teacher guide) (Israel Ministry of Education, Jerusalem, Israe, 2019).

[2] R. Bybee, P. Fensham, and R. Laurie, Scientific literacy and contexts in PISA 2006 science, J. Res. Sci. Teach. 46, 862 (2009).

[3] National Research Council, A Framework for K-12 Science Education: Practices, Crosscutting Concepts, and Core Ideas (The National Academies Press, Washington, DC, 2012).

[4] OECD, Assessing Scientific, Reading and Mathematical Literacy (OECD Publishing, Paris, France, 2006).

[5] N. W. Feinstein, S. Allen, and E. Jenkins, Outside the pipeline: Reimagining science education for nonscientists, Science 340, 314 (2013).

[6] L. D. Yore, B. M. Hand, and M. K. Florence, Scientists' views of science, models of writing, and science writing practices. J. Res. Sci. Teach. 41, 338 (2004).

[7] C. Dornan, Some problems in conceptualizing the issue of 'science in the media', in Communicating Science: Contexts, and Channels, edited by E. Scanlon, R. Hill, and K. Junker (Routledge, Abingdon, UK, 1999), pp. 179-205.

[8] L. K. Berland, C. V. Schwarz, C. Krist, L. Kenyon, A. S. Lo, and B. J. Reiser Epistemologies in practice: Making scientific practices meaningful for students, J. Res. Sci. Teach. 53, 1082 (2016).

[9] N.J. Nersessian, The cognitive basis of model-based reasoning in science, in The Cognitive Basis of Science, edited by P. Carruthers, S. Stich, and M. Siegal (Cambridge University Press, Cambridge, England, 2002), pp. 133153.

[10] J. Watkins, J. E. Coffey, E. F. Redish, and T. J. Cooke, Disciplinary authenticity: Enriching the reforms of introductory physics courses for life-science students, Phys. Rev. ST Phys. Educ. Res. 8, 010112 (2012).

[11] S. Kapon, A. Laherto, and O. Levrini, Disciplinary authenticity and personal relevance in school science, Sci. Educ. 102, 1077 (2018).

[12] C. A. Chinn and B. A. Malhotra, Epistemologically authentic inquiry in schools: A theoretical framework for evaluating inquiry tasks, Sci. Educ. 86, 175 (2002).
[13] O. Levrini, P. Fantini, B. Pecori, G. Tasquier, and M. Levin, Defining and operationalizing 'Appropriation' for science learning, J. Learn. Sci. 24, 93 (2015).

[14] J. Ryder, Identifying science understanding for functional scientific literacy, Stud. Sci. Educ. 36, 1 (2001).

[15] The National Academies, Rising above the Gathering Storm: Energizing and Employing America for a Brighter Economic Future (The National Academies Press, Washington, DC, 2007).

[16] G. Porat and S. Kapon, Building measurement devices with students-from hands-on to minds-on, Phys. Teach. 56, 461 (2018).

[17] S. Kapon and M. Schvartzer, Nurturing sensemaking of, through, and with a mathematical model, in Proceedings of the 2018 Physics Education Research Conference, Washington, DC, edited by A. Traxler, Y. Cao, and S. Wolf (AIP, New York, 2018).

[18] S. Kapon, Doing research in school: Physics inquiry in the zone of proximal development, J. Res. Sci. Teach. 53, 1172 (2016).

[19] NGSS Lead States, Next Generation Science Standards: For States, By States (The National Academies Press, Washington, DC, 2013).

[20] J. Osborne, Teaching scientific practices: Meeting the challenge of change, J. Sci. Teach. Educ. 25, 177 (2014).

[21] Adolescent Literacy in the Academic Disciplines: General Principles and Practical Strategies, edited by T. L. Jetton and C. Shanahan (Guildford Press, New York, 2012).

[22] J. L. Lemke, Talking Science: Language, Learning and Values (Ablex Publishing, New Jersey, 1990).

[23] S. P. Norris and L. M. Phillips, How literacy in its fundamental sense is central to scientific literacy, Sci. Educ. 87, 224 (2003).

[24] N. W. Feinstein, Salvaging science literacy, Sci. Educ. 95, 168 (2011).

[25] D. Layton, E. Jenkins, S. Macgill, and A. Davey, Inarticulate Science? Perspectives on the Public Understanding of Science and Some Implications for Science Education (Studies in Education, Driffield, East Yorkshire, 1993).

[26] W.-M. Roth and S. Lee, Scientific literacy as collective praxis, Publ. Understand. Sci. 11, 33 (2002). 
[27] N. W. Feinstein, Salvaging science literacy, Sci. Educ. 95, 168 (2011).

[28] M. Stuckey, A. Hofstein, R. Mamlok-Naaman, and I. Eilks, The meaning of 'relevance' in science education and its implications for the science curriculum, Stud. Sci. Educ. 49, 1 (2013).

[29] D. L. Ball, With an eye on the mathematical horizon: Dilemmas of teaching elementary school mathematics, Elem. Sch. J. 93, 373 (1993).

[30] D. Hammer and E. van Zee, Seeing the Science in Children's Thinking: Case Studies of Student Inquiry in Physical Science (Heinemann, London, 2006).

[31] D. Hammer, Discovery learning and discovery teaching, Cognit. Instr. 15, 485 (1997).

[32] J. Richards and A. D. Robertson, A review of research on responsive teaching in science and mathematics, in $R e$ sponsive Teaching in Science and Mathematics, edited by A. D. Robertson, R. E. Scherr, and D. Hammer (Routledge, London, 2016), pp. 36-55.

[33] B. Warren, C. Ballenger, M. Ogonowski, A. S. Rosebery, and J. Hudicourt-Barnes, Rethinking diversity in learning science: The logic of everyday sense-making, J. Res. Sci. Teach. 38, 529 (2001).

[34] A. S. Rosebery, B. Warren, and F. R. Conant, Appropriating scientific discourse: Findings from language minority classrooms. J. Learn. Sci. 2, 61 (1992).

[35] M. Bang, D. Medin, and K. Washinawatok, Innovations in culturally based science education through partnerships and community, in New Science of Learning: Cognition, Computers and Collaboration in Education, edited by M. S. Khine and I. M. Saleh (Springer, New York, 2010), pp. 569-592.

[36] M. Bang and D. Medin, Cultural processes in science education: Supporting the navigation of multiple epistemologies, Sci. Educ. 94, 1008 (2010).

[37] I. Sánchez Tapia, J. Krajcik, and B. Reiser, "We do not know what is the real story anymore": Curricular contextualization principles that support indigenous students in understanding natural selection. J. Res. Sci. Teach. 55, 348 (2018).

[38] S. J. Basu and A.C. Barton, Developing a sustained interest in science among urban minority youth, J. Res. Sci. Teach. 44, 466 (2007).

[39] D. J. Griffiths, Introduction to Electrodynamics (Cambridge University Press, Cambridge, England, 2017).

[40] J. D. Jackson, Classical Electrodynamics (John Wiley and Sons, New York, NY, 1999).

[41] S. Kapon, U. Ganiel, and B.-S. Eylon, Goals and design of public physics lectures: Perspectives of high-school students, physics teachers and lecturers, Phys. Educ. 44, 528 (2009).
[42] S. Kapon, U. Ganiel, and B. S. Eylon, Explaining the unexplainable: Translated Scientific Explanations (TSE) in public physics lectures, Int. J. Sci. Educ. 32, 245 (2010).

[43] D. Gentner, Structure-mapping: A theoretical framework for analogy, Cogn. Sci. 7, 155 (1983).

[44] M. B. Hesse, Models and Analogies in Science (University of Notre Dame Press, South Bend, IN, 1966).

[45] J. Clement, Using bridging analogies and anchoring intuitions to deal with students' preconceptions in physics, J. Res. Sci. Teach. 30, 1241 (1993).

[46] D. L. Schwartz, The construction and analogical transfer of symbolic visualizations, J. Res. Sci. Teach. 30, 1309 (1993).

[47] G. Lakoff and M. Johnson, Metaphors We Live By (University of Chicago Press, Chicago, IL, 1980).

[48] G. Fauconnier and M. Turner, Blending as a central process of grammar, in Conceptual Structure, Discourse, and Language, edited by A. Goldberg (CSLI Publications, Stanford, CA, USA, 1996), pp. 1113-130.

[49] S. M. Glynn, B. K. Britton, M. Semrud-Clikeman, and K. D. Muth, Analogical reasoning and problem solving in science textbooks, in Handbook of Creativity, edited by J. A. Glover, R. R. Ronning, and C. R. Reynolds (Plenum, New York, 1989), pp. 383-398.

[50] S. P. Norris, S. M. Guilbert, M. L. Smith, S. Hakimelahi, and L. M. Phillips, A theoretical framework for narrative explanation in science, Sci. Educ. 89, 535 (2005).

[51] J. Ogborn, G. Kress, I. Martins, and K. McGillicuddy, Explaining Science in the Classroom (The Open University Press, Buckingham, UK, 1996).

[52] J. S. Bruner, The narrative construction of reality, Crit. Inq. 18, 1 (1991).

[53] A. Borenstein, No radiation for you. Available at http:// www.norad4u.co.il/. (Accessed: 30th June 2019).

[54] World Health Organization. Electromagnetic fields (EMF). Available at https://www.who.int/peh-emf/about/Whatis EMF/en/index1.html. (Accessed: 30th June 2019).

[55] A. Gilad, How do we kill ourselves-Radiation (Hebrew). Reshet13 (2017). Available at http://reshet.tv/item/news/ documentary/season-01/episodes/zbuid-468588. (Accessed: 30th June 2019).

[56] J. Osborne, Arguing to learn in science: The role of collaborative, critical discourse, Science 328, 463 (2010).

[57] D. M. Kahan, Climate-science communication and the measurement problem, Polit. Psychol. 36, 1 (2015).

[58] National Academies of Sciences Engineering and Medicine, Science Literacy (National Academies Press, Washington, DC, 2016).

[59] A. J. Sharon and A. Baram-Tsabari, Can science literacy help individuals identify misinformation in everyday life?, Sci. Educ. 104, 873 (2020). 